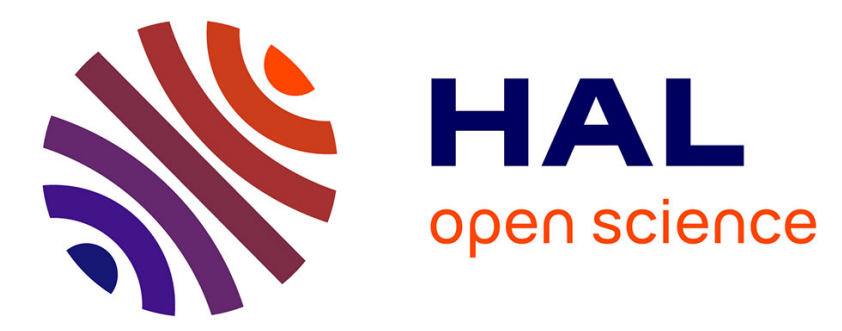

\title{
Incorporation of carbon nanotubes in a silica HPLC column to enhance the chromatographic separation of peptides: Theoretical and practical aspects
}

\author{
C. André, T. Gharbi, R. Aljhani, Y.-C. Guillaume
}

\section{- To cite this version:}

C. André, T. Gharbi, R. Aljhani, Y.-C. Guillaume. Incorporation of carbon nanotubes in a silica HPLC column to enhance the chromatographic separation of peptides: Theoretical and practical aspects. Journal of Separation Science, 2011, 34 (11), pp.1221-1227. 10.1002/jssc.201000903 . hal00607854

\section{HAL Id: hal-00607854 \\ https://hal.science/hal-00607854}

Submitted on 22 Apr 2021

HAL is a multi-disciplinary open access archive for the deposit and dissemination of scientific research documents, whether they are published or not. The documents may come from teaching and research institutions in France or abroad, or from public or private research centers.
L'archive ouverte pluridisciplinaire HAL, est destinée au dépôt et à la diffusion de documents scientifiques de niveau recherche, publiés ou non, émanant des établissements d'enseignement et de recherche français ou étrangers, des laboratoires publics ou privés.

\section{(c)(1)}

Distributed under a Creative Commons Attribution| 4.0 International License 


\title{
Incorporation of carbon nanotubes in a silica HPLC column to enhance the chromatographic separation of peptides: Theoretical and practical aspects
}

\author{
Claire André ${ }^{1,2}$ \\ Rania Aljhani ${ }^{1,2}$ \\ Tijani Gharbi ${ }^{1,2}$ \\ Yves C. Guillaume ${ }^{1,3}$ \\ ${ }^{1}$ Université de Franche Comté, Besancon, France \\ ${ }^{2}$ Nanomedecine Lab, Imagery, Therapeutic (EA4267), Laboratoire de Chimie Analytique et Physique, Besancon, France \\ ${ }^{3} \mathrm{CHU}$ Besancon, Po^ le Pharmaceutique, Besancon, France
}

\begin{abstract}
The retention mechanism of a series of peptides on a single-wall carbon nanotube (SWCNT) stationary phase inside an HPLC column was investigated over a wide range of mobile phase compositions. While the similar size C18 column exhibited an efficiency of $11.5 \mu \mathrm{m}$, the SWCNT column increased the efficiency, i.e. $7.10 \mu \mathrm{m}$ at a flow rate of $0.8 \mathrm{~mL} / \mathrm{min}$, and significantly affected the separation quality of the peptides. The values of enthalpy $(\Delta H)$ and entropy $\left(\Delta S^{*}\right)$ of transfer of the peptides from the mobile to the SWCNT stationary phase were determined. The method studied each factor, i.e. ACN fraction $x$ in the ACN/water mixture and column temperature. The changes in retention factor, $\Delta H$ and $\Delta S^{*}$ as a function of the ACN fraction in the mobile phase were examined. These variations are explained using the organization of ACN in clusters in the ACN/water mixture and on the steric and electronic forces implied in the retention process. The information obtained in this work makes this SWCNT stationary phase useful for peptide research and demonstrated the role of ACN to improve the separation quality.
\end{abstract}

\section{Keywords: Acetonitrile (ACN) / Peptides / Separation / Single-wall carbon nanotube}

\section{Introduction}

Nanoscience is a discipline concerned with making, manipulating, and imaging materials with at least one dimension smaller than $100 \mathrm{~nm}$. It can be divided into nanochemistry and nanotechnology. The former represents synthetic chemistry to prepare nanoscale building blocks of different size, shape, composition, surface structure, charge, and functionality and includes self-assembled structures, biological nanostructures, nano- and mesoporous materials, nanoparticles, nanotubes. Nanotechnology then concerns device, machine, product, or process based upon integrated nanoscale components. Due to unique properties of nanoparticles, such as their large surface-tovolume ratio and their properties that differ from those of corresponding bulk materials, the use of nanomaterials in separation science is growing rapidly [1-3]. Nanostructures such as fullerene derivatives, polymer latex nanoparticles have been used for the modification of separation media for application in chromatography and electrophoresis [4-11]. The use of nanoparticles was particularly studied in the

Correspondence: Dr. Yves C. Guillaume, CHU Besancon, Pôle Pharmaceutique, F-25000, Place Saint Jacques, Besancon 25030, France

E-mail: yves.guillaume@univ-fcomte.fr

Fax: $+33-3-81-66-56-55$

Abbreviation: SWCNT, single-wall carbon nanotube field of polymer monoliths. Methacrylate columns with attached functionalized polymer nanoparticles were developed first and used for the separation of saccharides and in ion chromatography [12-15]. Monoliths with pores coated with gold nanoparticles have recently been prepared and used for the pre-concentration of thiol-containing peptides and the separation of proteins [16, 17]. As well, single-wall carbon nanotubes (SWCNTs) [18-21] exhibit physical properties that make them potentially useful in separation science. An important factor that controls these properties comes from a variation of tubule structures that are caused by the rolling up of the graphene sheet into a tube. As well, hybridation of carbon in SWCNTs is $\mathrm{sp}^{2}$. Therefore, SWCNTs can establish electrostatic interactions (e.g. dipole-dipole), hydrogen bonds, $\pi-\pi$ stacking, dispersion forces, dative bonds, and hydrophobic effect. Chromatographic applications of these nanomaterials have thus been focused on their use as stationary phases in either GC [22-26] or LC [27, 28] while in CE they have been utilized as pseudostationary phases in CEC [29]. Nevertheless, the retention mechanism in LC of biomolecules on carbon nanotubes remains relatively unclear and the effect of some mobile phase organic modifier must be elucidated. In this paper, the influence of the mobile phase composition (i.e. the ACN fraction in the water/ACN mixture) and column temperature on the retention and separation of a series of peptides was investigated using a SWCNT column developed previously in our laboratory [11]. 


\section{Materials and methods}

\subsection{Apparatus and columns used}

The HPLC system consisted of waters HPLC pump 501 (Saint-Quentin, Yvelines, France), an Interchim rheodyne injection valve, Model 7125 (Interchim, Montluçon, France), fitted with a reverse $20 \mu \mathrm{L}$ sample loop, a Merck L4000 variable-wavelength UV spectrophotometer detector, and a Merck D2500 chromato-integrator (Nogent sur Marne, France). The silica Kromasil column ( $3.5 \mu \mathrm{m}$ particle size, $50 \mathrm{~mm} \times 4.6 \mathrm{~mm}$ column size) was furnished by Interchim. The similar size C18 column was also furnished by Interchim. The in situ process for the preparation of the SWCNT column $(50 \mathrm{~mm} \times 4.6 \mathrm{~mm})$ was given in [11]. This immobilization process consists of the attachment of CNT$\mathrm{NH}_{2}$ directly in a pre-packed column. Briefly, the silanol groups of the Kromasil silica stationary phase are silylated with 3-aminopropyl triethoxysilane. The aminopropyl silica Kromasil column was then activated by recycling a $5 \%$ aqueous solution of glutardialdehyde for $10 \mathrm{~h}$ at $0.5 \mathrm{~min} /$ min in the dark. CNT-NH$H_{2}$ is then immobilized to the silica gel by imine formation between the aldehyde group and one or more amino groups in the CNT-NH$H_{2}$. For this, a solution of $2 \mathrm{~g} / \mathrm{L}$ of CNT- $\mathrm{NH}_{2}$ in the methanol/phosphate buffer $(\mathrm{pH}$ 7.0) $(0.15: 0.85 \mathrm{v} / \mathrm{v})$ was pumped through the support at $0.5 \mathrm{~mL} / \mathrm{min}$ for $16 \mathrm{~h}$, flushing and back-flushing every $15 \mathrm{~h}$ during the first hour, every $30 \mathrm{~min}$ during the following $3 \mathrm{~h}$. After immobilization, a subsequent reduction of the resulting double bonds was performed with sodium borohydride. Finally, the unreacted aldehyde groups were capped with monoethanolamine. Mobile phase flow-rate for most experiments was $0.8 \mathrm{~mL} / \mathrm{min}$. The column was thermostated using an oven TM 701 (Interchim) for high temperature.

\subsection{Solvents and samples}

HPLC grade ACN (Merck) was used without further purification. Water was obtained from an Elgastat water purification system (Odil, Talant, France), fitted with a reverse osmosis cartridge. The mobile phase used was an $\mathrm{ACN} /$ water mixture. The ACN fraction ranged from 0.05 to $0.95 \mathrm{v} / \mathrm{v}$. The chemical structures of the 12 peptides (CASLO Laboratory ApS, Lyngby, Denmark) with purities $>98 \%$ are given in Table 1. Each solute was injected five times and the retention times were measured.

\subsection{Temperature studies}

Compound retention factors were determined over the temperature ranged $20-60^{\circ} \mathrm{C}$. The chromatographic system was allowed to equilibrate at each temperature for at least $1 \mathrm{~h}$ prior to each experiment. To study this equilibration, the compound retention time of compound (pep. 3) (see
Table 1. Peptide structures

\begin{tabular}{ll}
\hline Peptide number & Structures \\
\hline Pep.1 & Tyr Phe \\
Pep.2 & PheTyr \\
Pep.3 & Phe Pro \\
Pep.4 & Phe Gly \\
Pep.5 & Phe Leu \\
Pep.6 & Glu Cyst \\
Pep.7 & Tyr Gly \\
Pep.8 & Arg Phe \\
Pep.9 & Phe Glu \\
Pep.10 & Tyr Arg \\
Pep.11 & Phe Arg \\
Pep.12 & Gly Gly \\
\hline
\end{tabular}

structure in Table 1) was measured every hour for $7 \mathrm{~h}$ and again after 22, 23, and $24 \mathrm{~h}$. The maximum relative difference in the retention times of this compound between these different measurements was always $0.3 \%$, making the chromatographic system sufficiently equilibrated for use after $1 \mathrm{~h}$.

\subsection{Thermodynamic relationships}

Solute retention is usually expressed in terms of the retention factor $k$ by the equation:

$\ln k=-\frac{\Delta H}{R T}+\frac{\Delta S}{R}+\ln \delta$

where $\Delta H$ and $\Delta S$ are, respectively, the enthalpy and entropy for the transfer of the peptide molecule from the mobile to the SWCNT stationary phase, $T$, the temperature, $R$, the gas constant, and $\delta$ the phase ratio (volume of the stationary phase divided by the volume of the mobile phase). This equation showed that for a linear plot of $\ln k$ versus $1 / T$ (called the van't Hoff plot) the slope and intercept are, respectively, equal to $-\Delta H / R$ and $\Delta S^{*}(=\Delta S / R+\ln \delta)$. This provides a convenient way of calculating the thermodynamic data $\Delta H$ and $\Delta S$ for a chromatographic system if the phase ratio is known or can be calculated. Although $\Delta S$ is not usually provided, because of the ambiguity of the phase ratio, $\Delta S^{*}$ varies identically with $\Delta S$.

\subsection{Enthalpy-entropy compensation}

Investigation of the enthalpy-entropy compensation temperature is a useful thermodynamic approach to the analysis of physicochemical data [30].

$\Delta H=\beta \Delta S+\Delta G_{\beta}$

where $\Delta G_{\beta}$ is the Gibbs free energy of physicochemical interaction at a compensation temperature $\beta$ and $\Delta H$ and $\Delta S$ are the corresponding standard enthalpy and entropy, respectively. According to Eq. (2) when enthalpy-entropy 
compensation is observed for the retention of a solute molecule when the mobile phase composition (i.e. the ACN fraction $x$ in the mobile phase) changed, this molecule had the same free energy $\Delta G$ at the compensation temperature $\beta$ for all the $x$ values studied. Combining Eqs. (1) and (2) gives the following equation:

$\ln k_{T}=\ln k_{\beta}-\frac{\Delta H}{R}\left(\frac{1}{T}-\frac{1}{\beta}\right)$

$\ln k_{\beta}=-\frac{\Delta G_{\beta}}{R \beta}+\ln \delta$

Equation (3) demonstrated that if the slope of the plot $\ln k$ versus $-\Delta H$ (or if the $\beta$ value) for a given solute molecule was not identical in the entire ACN fraction range in the mobile phase, a change of its retention mechanism was observed [30].

\section{Results and discussion}

\subsection{Separation performance}

The chromatographic stability of the SWCNT column has been tested. The column stability was tested by comparing the column efficiency and the retention factor determined with pep. 3 during the study and after 4 months in the same conditions, i.e. an ACN/water (20:80, v/v) mixture as mobile phase with a flow rate of $0.8 \mathrm{~mL} / \mathrm{min}$, a column temperature equal to $20^{\circ} \mathrm{C}$, and a back pressure of 41 bar. The column efficiency (height equivalent to a theoretical plate (HETP)) and the logarithm of the pep. 3 retention factor were respectively equal to $7.10 \mu \mathrm{m}$ and 0.78 . The maximum relative difference between these values was never more than $0.6 \%$, proving the stability of the SWCNT column during an extended period of time. The similar size C18 column in the same experimental chromatographic conditions affords an efficiency of $11.5 \mu \mathrm{m}$ for pep. 3. The efficiency of the SWCNT column thus exhibits a significant increase compared to the C18 column as demonstrated by the separation of the 12 peptides shown in Fig. 1.

\subsection{Variation of the peptide retention on the SWCNT stationary phase with ACN fraction}

The influence of the mobile phase composition on the retention behaviour of the peptides was studied for a wide range of column temperatures. Figure 2 reports the data acquired on the evolution of the retention factor of pep. 3 when the ACN fraction $x$ in the mobile phase increased from 5 to $95 \% \mathrm{v} / \mathrm{v}$ for a column temperature equal to $20^{\circ} \mathrm{C}$. Figure 3 represented the variation of the retention factor for pep. 3 versus the ACN fraction in the mobile phase $x$ and the column temperature T. From Fig. 2 it is evident that the trend $\ln k$ versus $x$ is not linear and a similar quadratic variation was observed for all the other peptides at all the
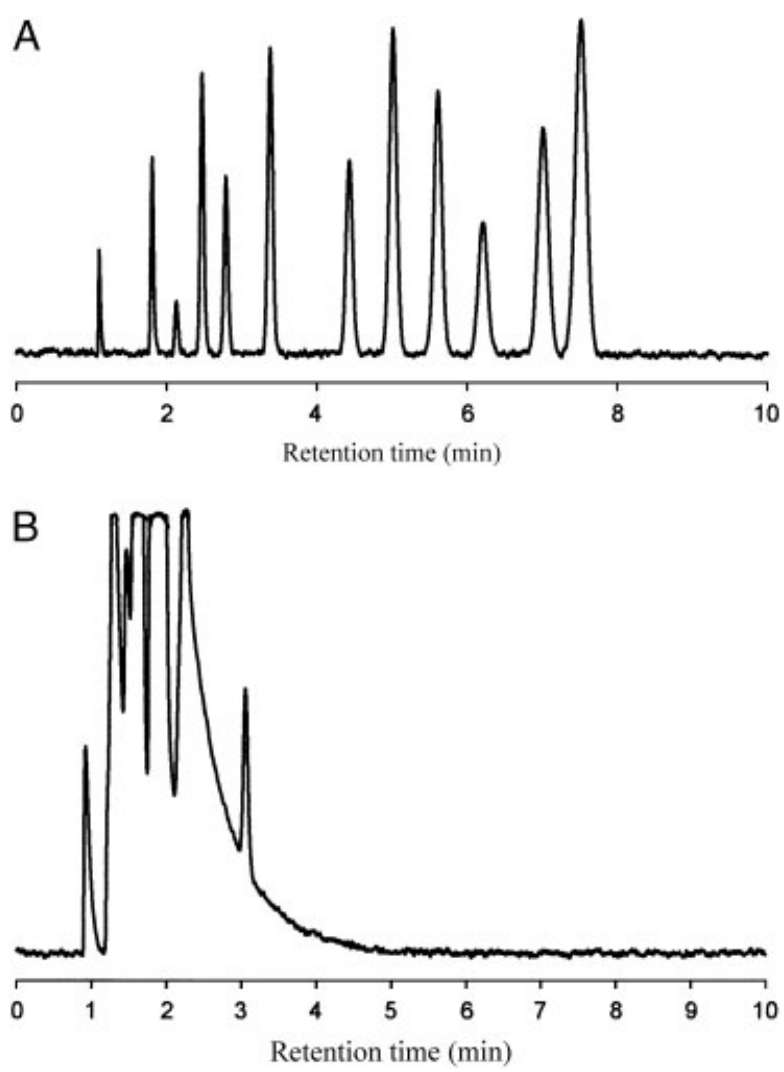

Figure 1. Separation of the 12 peptides on the SWCNT (A) and C18 (B) column using an ACN fraction in the ACN/water mixture equal to 0.05 with a column temperature equal to $55^{\circ} \mathrm{C}$ and a flow rate equal to $0.8 \mathrm{~mL} / \mathrm{min}$. Characteristics of the two columns: $3.5 \mu \mathrm{m}$ particle size, $50 \mathrm{~mm} \times 4.6 \mathrm{~mm}$ column size. For (A) and (B) the first peak corresponded to pep. 12 and the last peak to pep. 1.

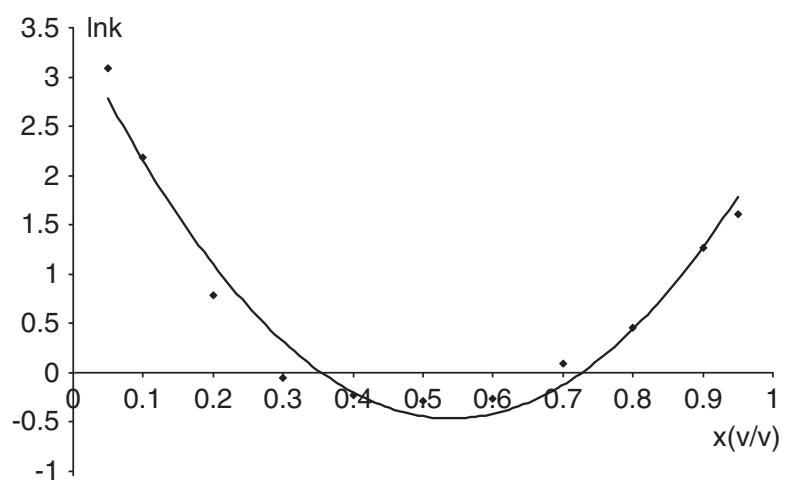

Figure 2. Plot of $\ln k$ versus the fraction of $A C N(x)$ in the water/ ACN mixture at $20^{\circ} \mathrm{C}$ for pep. 3.

temperatures studied. The simple polynomial of quadratic form was thus adopted and was as follows [31]:

Ln $k=a x^{2}+b x+c$

where $a, b$, and $c$ are empirical coefficients. In reversed phase LC it was shown that this equation gave relatively 
good correlation coefficients, but inherently, the parameters $a, b$, and $c$ do not correlate with any properties of solutes or organic modifiers [31]. This equation fits well because of logarithm scale and more parameters to be fixed. By using non-linear regression and for each peptide and column temperature the non-linear regression was determined $\left(r^{2} \geq 0.961\right)$. From the full regression model, a Student $t$ test was used to provide the basis for the decision about whether or not the model coefficients were significant. Results of Student's $t$-test show that no variables can be excluded from the model. For example, for pep. 3, for a column temperature equal to $293 \mathrm{~K}$ the $a, b$, and $c$ coefficients of Eq. (5) were respectively equal to 13.46, -14.55 , and $3.47\left(r^{2}=0.964\right)$. These results confirmed that the linear solvent strength model [32] cannot be applied in a broad range of mobile phase compositions. For each temperature, the peptide retention decreased with increasing concentration of $\mathrm{ACN}$ in the lower fraction range,

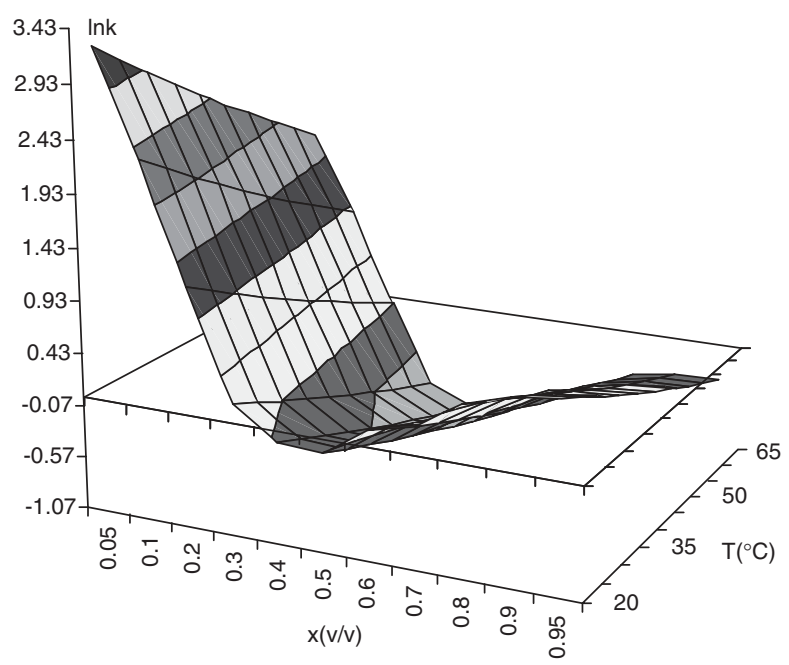

Figure 3. Plot of In $k$ versus the fraction of $\operatorname{ACN}(x)$ in the water/ ACN mixture and column temperature $T\left({ }^{\circ} \mathrm{C}\right)$ for pep. 3 . reached a minimum and increased again with increasing fraction of ACN in the higher fraction range (Figs. 2 and 3). As well, for each $x$ value, the retention order of the peptide was always the same, i.e. pep. (i) > pep. (i+1) (see Table 1).

\subsection{Possible thermodynamic origins of the peptide binding to SWCNT}

According to Eq. (1) van't Hoff plots were obtained for all peptides. The correlation coefficients for the linear fit were in excess of 0.999 . For example, Fig. 4 gave the van't Hoff plots for pep. 3 for all the $x$ values studied. Considering pep. 3 with an ACN fraction equal to $0.70, \Delta H$ was found to be equal to $-17.1 \mathrm{~kJ} / \mathrm{mol}$ and $\Delta S^{*}$ was calculated to be -6.8 . As well, Table 2 gave the thermodynamic data for all the peptides for an ACN fraction equal to 0.05. Both $\Delta H$ and $\Delta S^{*}$ were negatives for all the peptides and all $x$ values. As $\Delta H$ became more negative, the solute was retained longer, as $\Delta S^{*}$ became more negative the solute was retained less. Figures 5 and 6 showed $\Delta H$ and $\Delta S^{*}$, respectively, versus $\mathrm{ACN}$ fraction in the ACN/water mixture for pep. 3. These variations were the same for all the other peptides. $\Delta H$ and $\Delta S^{*}$ were found to exhibit a quadratic variation. When $x$ was $\leq$ to a critical value $x_{c}$, these thermodynamic data increased with $x$ and when $x \geq x_{c}$ these values decreased with $x$. Enthalpy-entropy compensation as described in Eq. (3) was also applied. Two plots of $\ln k$ against $-\Delta H$ for region I $\left(x \leq x_{c}\right)$ and II $\left(x \geq x_{c}\right)$ were drawn for all the peptide molecules. The correlation coefficients for the linear fits were always $\geq 0.98$ in region I and 0.97 in region II. Examples of these plots are given in Figs. 7 and 8 for pep. 3 . As well, these two linear plots in regions I and II had for all the peptides different slopes, i.e. different $\beta$ values. For example for pep. $3 \beta$ region $\mathrm{I}=512 \mathrm{~K} \neq \beta$ region $\mathrm{II}=828 \mathrm{~K}$ (Figs. 7 and 8 ). These results confirmed the different interaction mechanisms in regions I and II. To explain these variations the following model is proposed based on

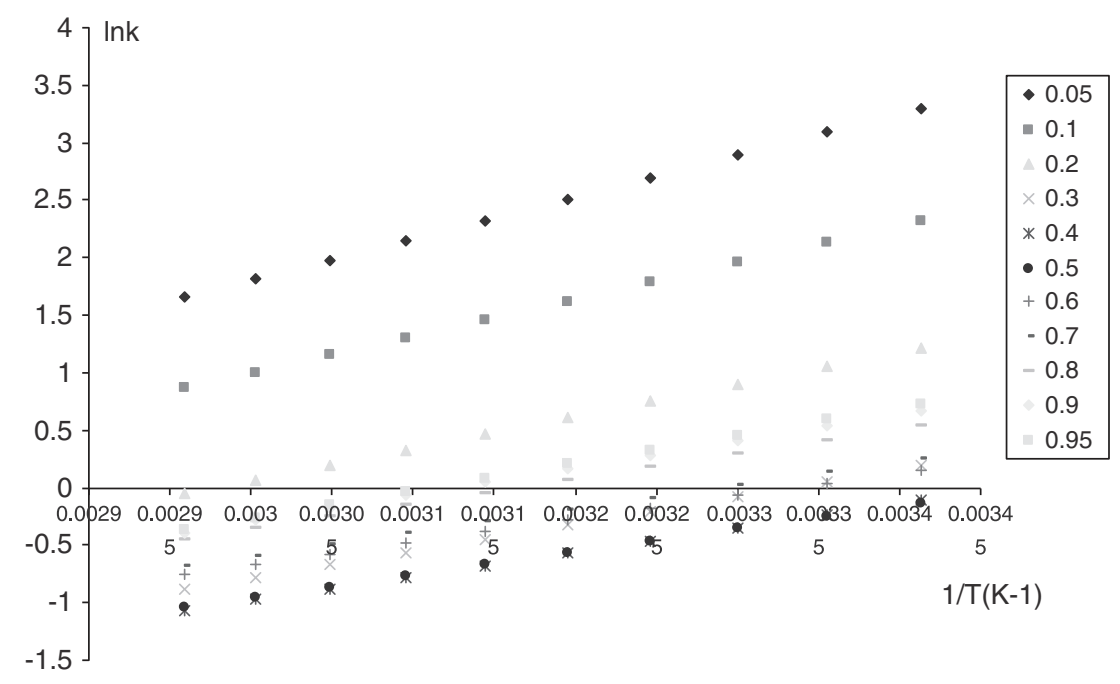

Figure 4. Plot of $\ln k$ versus $1 / T\left(\mathrm{~K}^{-1}\right)$ for pep. 3 for the 11 values of the fraction of $\operatorname{ACN}(x)$ in the water/ACN mixture. 
Table 2. $\Delta H(\mathrm{~kJ} / \mathrm{mol})$ and $\Delta \mathrm{S} *$ values for an $\mathrm{ACN}$ fraction $(x)$ i n the water/ACN mixture equal to 0.05

\begin{tabular}{llr}
\hline Peptide number & $\Delta H(\mathrm{~kJ} / \mathrm{mol})$ & $\Delta S *$ \\
\hline 1 & -33.4 & -10.1 \\
2 & -33.1 & -10.0 \\
3 & -30.0 & -9.0 \\
4 & -28.4 & -8.5 \\
5 & -26.4 & -8.0 \\
6 & -26.2 & -7.9 \\
7 & -24.0 & -7.4 \\
8 & -23.0 & -7.3 \\
9 & -21.9 & -7.1 \\
10 & -21.0 & -6.9 \\
11 & -20.0 & -6.7 \\
12 & -18.0 & -6.1 \\
\hline
\end{tabular}

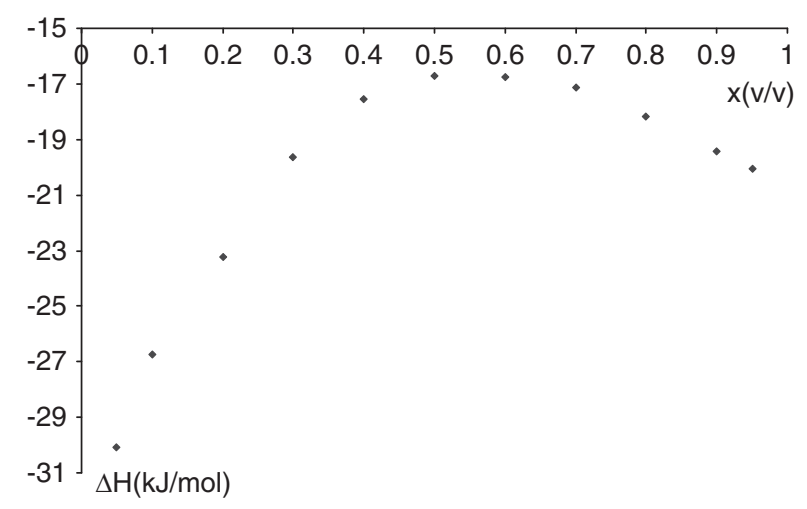

Figure 5. Plot of $\Delta H(\mathrm{~kJ} / \mathrm{mol})$ versus the fraction of $\mathrm{ACN}(x)$ in the water/ACN mixture for pep. 3.

the particular way that ACN is organized in clusters in the ACN/water mixture [33-36].

It was previously demonstrated that the variation of the "free" ACN (not in a cluster) in the ACN/water mixture versus the water fraction is a sigmoidal curve and presented an inflexion point around a critical value of $\mathrm{ACN}$ fraction around 0.50 . It is remarkable that the optimum point obtained on Figs. 2, 3, 5, and 6 was obtained around this value. Thus, from this cluster model, the following conclusions can be drawn:

(i) For a low ACN fraction $x\left(x \leq x_{c}\right)$, the number and size of ACN clusters is very weak [36]. When $x$ increased, the number of clusters increased [36] and the peptide solvation with these clusters increased, thus leading to a peptide retention decrease. The SWCNT-peptide interaction decreased (Fig. 2) and the peptide molar enthalpy and entropy associated with the SWCNT surface increased strongly, leading to an increase in the solute transfer thermodynamic data $\Delta H$ and $\Delta S^{*}$ when $x$ increased (Figs. 5 and 6).

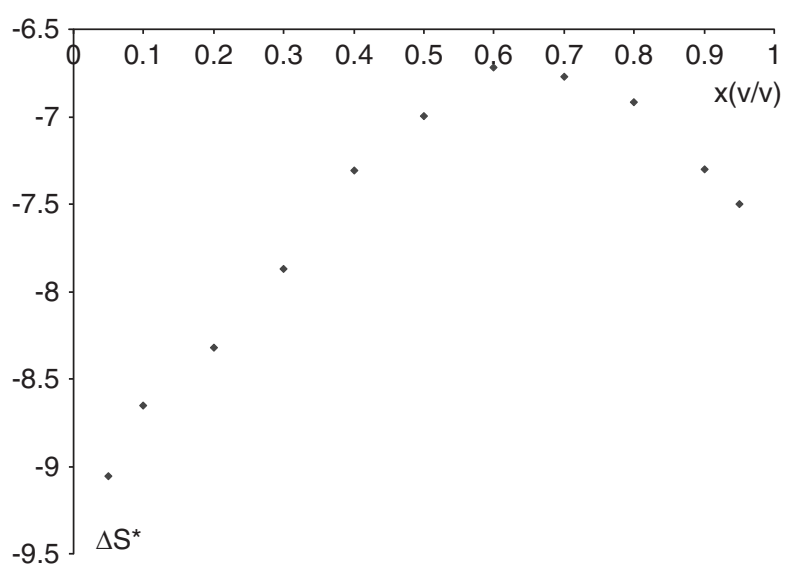

Figure 6. Plot of $\Delta S^{*}$ versus the fraction of $\mathrm{ACN}(x)$ in the water/ ACN mixture for pep. 3 .

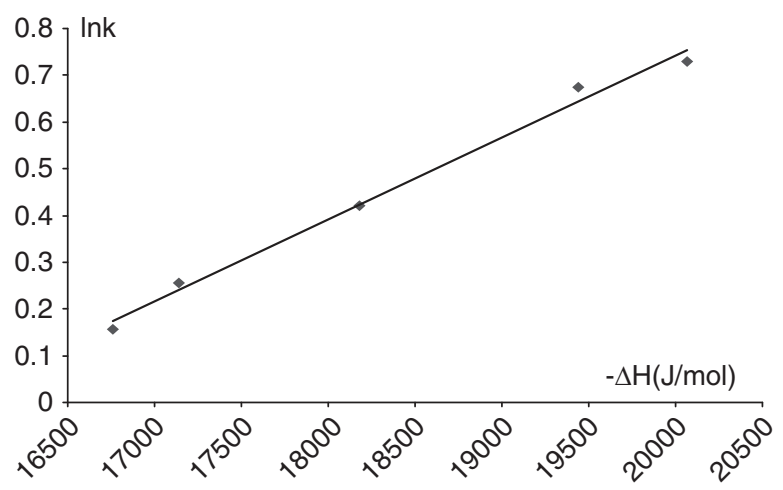

Figure 7. Plot of $\ln k$ versus $-\Delta H(\mathrm{~J} / \mathrm{mol})$ for the fraction of $A C N$ $(x)$ in the water/ACN mixture $\leq 0.5$ (region I) and for pep. 3 .

(ii) For a high ACN concentration $x\left(x \leq x_{c}\right)$, in this region, most of the ACN molecules were organized in clusters [36]. The high concentration of these clusters suppresses the dissociation of the polar substructures in peptides, resulting in increased apparent hydrophobicity. As hydrophobic compounds may attach more strongly to the SWCNT surface, the apparent increase in hydrophobicity may account for the peptide retention increase when $x$ increases (Fig. 2). Thus, the peptide molecule comes into increasingly more contact with SWCNT surface and $\Delta H$ and $\Delta S^{*}$ thus decreased when $x$ increased (Figs. 5 and 6). It was interesting to note that the smallest thermodynamic data between the 12 peptides were obtained for peptides containing two aromatic rings in their structures, i.e. pep. 1, pep. 2, and pep. 3 for each $x$ value. For example, the $\Delta H$ values obtained with $x=0.70$ for pep. 6; pep. 4 and pep. 1 were respectively equal to $-13.81,-14.12$, and $-18.1 \mathrm{~kJ} / \mathrm{mol}$. This result confirmed the fact that polar interactions between peptides and the SWCNT surface played a great role with the hydrophibicity in the peptide-SWCNT retention process. These polar interactions are related to the CNT structure, which can be 


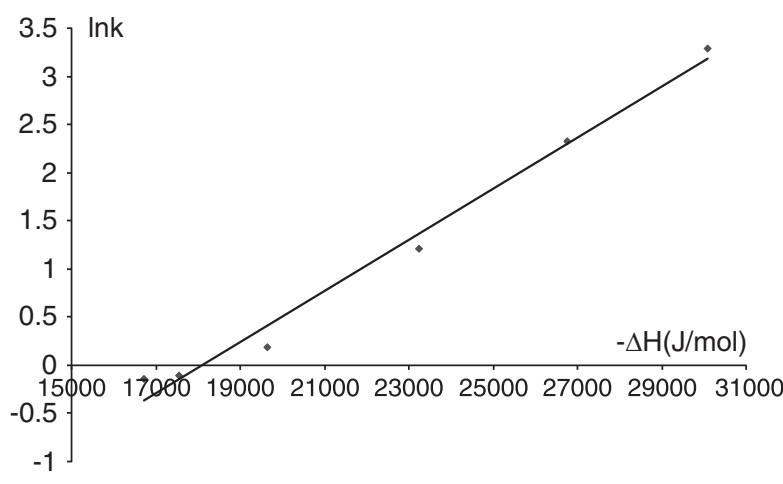

Figure 8. Plot of $\ln k$ versus $-\Delta H(\mathrm{~J} / \mathrm{mol})$ for the fraction of $A C N$ $(x)$ in the water/ACN mixture $\geq 0.5$ (region II) and for pep. 3 .

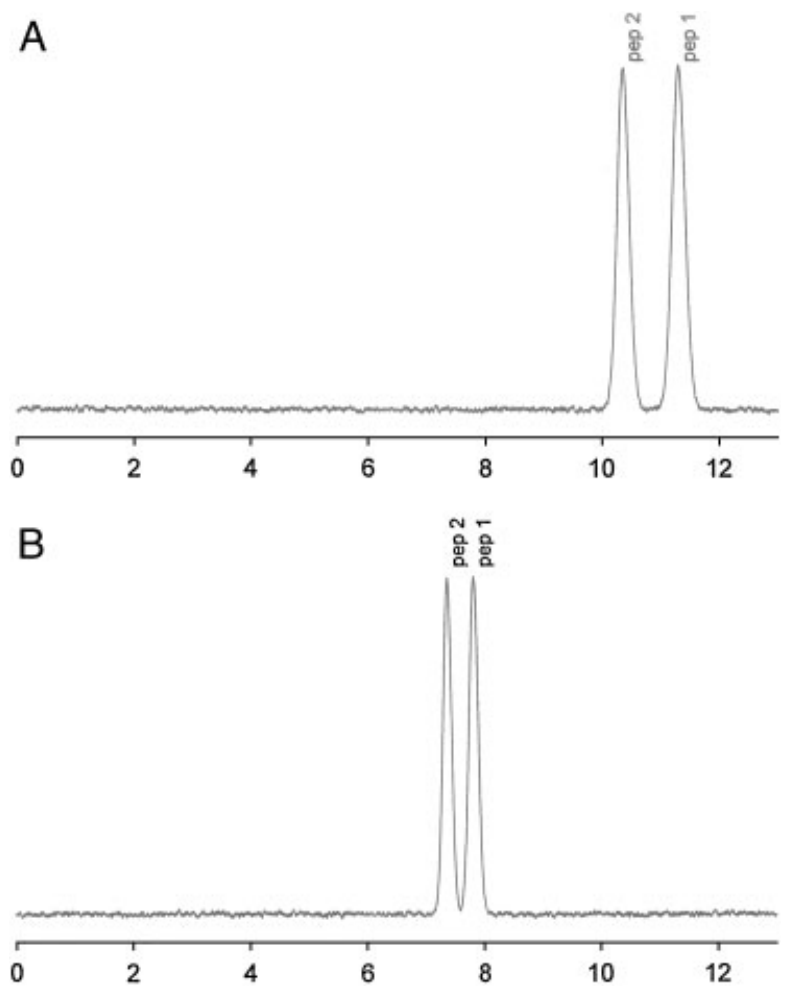

Figure 9. Chromatograms obtained for the mixture of pep. 1 and pep. 2 for (A) $x=0.70$ and (B) $x=0.55$ at $T=20^{\circ} \mathrm{C}$ ( $x$ was the fraction of $A C N$ in the water/ACN mixture).

viewed as graphite sheet $\left(\mathrm{sp}^{2}\right)$ carbon that has been rolled up into a tiny tube. There is thus growing evidence to suggest that polar interactions have a significant influence on retention. This effect can be explained by the assumption that the ring structure of Phe and Tyr is probably bonded to the hexagonal graphitic substructures on the SWCNT surface by stacking interactions influencing in this manner the retention behaviour of these derivatives. Since the polar interactions between atoms is proportional to $1 /$ $r^{n}(n>1)$ where $r$ is the distance between atoms, a small decrease in $r$ will greatly increase the energy of interaction. As well, since the nanotubes are full of $\pi$ electrons the aromatic ring of Tyr or Phe is likely to interact with the surface of tubes through $=\mathrm{CH}-\pi$ hydrogen bonds as previously demonstrated for polycyclic aromatic hydrocarbons [37]. These results would thus explain the variation curves of $\ln k, \Delta H$, and $\Delta S^{*}$ in relation to $x$, which had an optimum value around $x=0.50$ (Figs. 2, 3, 5, and 6). The variation of both the retention factors and thermodynamic data with the ACN fraction illustrates the importance of a careful optimisation of the parameters of separation. The chromatogram obtained for the mixture of pep. 1 and pep. 2 for $x=0.70$ at $20^{\circ} \mathrm{C}$ is given in Fig. 9A. The corresponding analysis time is around $12 \mathrm{~min}$. So as to reduce the analysis time, the separation was carried for $x=0.55$ at the same temperature (Fig. 9B). The corresponding analysis time was around $8 \mathrm{~min}$ and pep. 1 and pep. 2 were always separated.

\section{Concluding remarks}

In this paper the retention mechanism of a series of peptides was analysed on a SWCNT stationary phase. The thermodynamic properties trends were determined over a wide range of $\mathrm{ACN}$ fraction $x$ in the $\mathrm{ACN} /$ water mixture. The model proposed explains these variations in terms of organization of the organic modifier (ACN) in clusters in the ACN/water mixture and on the steric and specific electronic forces due to the unique structure of SWCNT. As well, the importance of the role of ACN to reduce the analysis time without diminishing the separation quality was clearly visualized.

The authors have declared no conflict of interest.

\section{References}

[1] Nilsson, C., Nilsson, S., Electrophoresis 2006, 27, 76-83.

[2] Nilsson, C., Birnbaum, S., Nilsson, S., J. Chromatogr. A 2007, 1168, 212-224.

[3] Zhang, Z., Wang, Z., Liao, Y., Liu, H., J. Sep. Sci. 2006, 29, 1872-1878.

[4] Ghihen, E., Glennon, J. D., Anal. Lett. 2003, 36, 3309-3336.

[5] Zhang, Z. X., Yan, B., Liao, Y. P., Liu, H. W., Anal. Bioanal. Chem. 2008, 391, 925-927.

[6] Qu, Q. S., Shen, F., Shen, M., Hu, X. Y., Yang, G. J., Wang, C. Y., Yan, C., Zhang, Y. K., Anal. Chim. Acta 2008, 609, 76-81.

[7] Tran, C. D., Challa, S., Analyst 2008, 133, 455-464.

[8] Liu, F. K., Hsu, Y. T., Wu, C. H., J. Chromatogr. A 2005, 1083, 205-214. 
[9] Jimenez-Soto, J. M., Moliner-Martinez, Y., Cardenas, S., Valcarcel, M., Electrophoresis, 2010, 31, 1681-1688.

[10] Zhong, Y., Zhou, W., Zhang, P., Zhu, Y., Talanta 2010, 82, 1439-1447.

[11] Andre, C., Gharbi, T., Guillaume, Y. C., J. Sep. Sci. 2009, 32, 1757-1764.

[12] Hilder, E. F., Svec, F., Frechet, J. M. J., J. Chromatogr. A. 2004, 1053, 101-106.

[13] Hutchison, J. P., Zakaria, P., Bowie, A. R., Macka, M., Avdalovic, N., Haddad, P. R., Anal. Chem. 2005, 77, 407-416.

[14] Glenn, K. M., Lucy, C. A., Haddad, P. R., J. Chromatogr. A 2007, 1155, 8-14.

[15] Xu, Y., Cao, Q., Svec, F., Frechet, J. M., J. Anal. Chem. 2010, 82, 3352-3358.

[16] Cao, Q., Xu, Y., Liu, F., Svec, F., Frechet, J. M., J. Anal. Chem. 2010, 82, 7416-7421.

[17] Connoly, D., Twamley, B., Paull, B., Chem. Commun. 2010, 46, 2109-2111.

[18] lijima, S. Q., Nature 1991, 354, 56-58.

[19] Uchiyama, H., Kaneko, K., Oseki, S., J. Chem. Soc.1987, 85, 4326-4333.

[20] Lijima, S. Q., Ichibashi, T., Nature 1993, 363, 603-605.

[21] Bethune, D. S., Klang, C. H., De Vries, M. S., Gorma, G., Savoy, R., Vasquez, J., Beyers, R., Nature 1993, 363, 605-607.

[22] Li, Q. L., Yuan, D. X., J. Chromatogr. A 2003, 1003, 203-209.

[23] Saridara, C., Mitra, S., Anal. Chem 2005, 77, 7094-7097.
[24] Karwa, M., Mitra, S., Anal. Chem. 2006, 78, 2064-2070.

[25] Stadermann, M., McBrady, A. D., Dick, B., Reid, V. R., Noy, A., Synovec, R. E., Bakajin, O., Anal. Chem. 2006, 78, 5639-5644.

[26] Yuan, L. M., Ren, R. N., Li, L., Ai, P., Yan, Z. H., Zi, Z., Li, Y., Anal. Chem. 2006, 78, 6384-6390.

[27] Li, Y., Chen, Y., Xiang, R., Ciuparu, D., Pfefferle, L. D., Horvath, C., Wilkins, J. A., Anal. Chem. 2005, 77, 1398-1406.

[28] Li, Y., Chen, R., Xiang, R., Cinparu, D., Pfefferle, L. D., Horvath, C., Wilkins, J. A., Anal. Chem. 2005, 77, 1398-1406.

[29] Sombra, L., Moliner-Martnez, Y., Cardenas, S., Valcarcelk, M., Electrophoresis 2008, 29, 3850-3857.

[30] Sander, L. C., Field, L. R., Anal. Chem. 1980, 42, 2009-2013.

[31] Row, K. H., J. Chromatogr. A. 1998, 797, 23-31.

[32] VanDeemter, J. J., Zuiderweg, F. J., Klinkenberger, A., Chem. Eng. Sci. 1956, 5, 271-289.

[33] Stalcup, A. M., Martire, D. E., Wise, S. A., J. Chromatogr. 1988, 442, 1-14.

[34] Lowenschuss, A., Yellin, N., Spectrochim. Acta 1975, 31A, 207-212.

[35] Rowlen, K. L., Harris, J. M., Anal. Chem. 1991, 63, 964-969.

[36] Guillaume, Y. C., Guinchard, C., Anal. Chem. 1996, 68, 2869-2873.

[37] Chang, Y. X., Zhou, L. L., Li, G. X., Li, L., Yuan, L. M., J. Liq. Chromatogr. Relat. Technol. 2007, 30, 2953-2958. 